12 Berger, R. J., and Oswald, I., Science, 137, 601 (1962).

13 Lewis, H. B., Goodenough, D. R., Shapiro, A., and Sleser, I., J. Abnorm. Psychol., 71, 52 (1966).

14 Antrobus, J. S., Dement, W. C., and Fisher, C., J. Abnorm. Soc. Psychol., 69, 341 (1964).

15 Hadamard, J., The Psychology of Invention in the Mathematical Field (Dover, New York, 1954).

16 Freud, S., The Interpretation of Dreams (Hogarth Press, London, 1953).

\section{Basic Rectangle of the Mandible in the Hominoidae}

KINZEY's letter to Nature ${ }^{1}$ calls for a reply. I do not criticize him, of course, for preferring to translate my visual "basic rectangle" into a standard type of index, which he calls "the BRM index", but it is his attempt to utilize this index to refute my claim that Kenyapithecus africanus is taxonomically within the family Hominidae that requires critical comment.

So far as I am aware, neither I nor anybody else has attempted to use evidence based on the basic rectangle of the mandible, for taxonomic purposes, beyond the limits of the superfamilythe Hominoidae. Kinzey's attempt therefore to introduce evidence from representatives of other families of the order primates, even including the Tarsoidea and Ceboidae, is irrelevant to the argument about the taxonomic value of the basic rectangle in studies of the Hominoidae.

Kinzey's communication seems to be special pleading. He entitled his Fig. 1 as follows, "Basic rectangle of the mandible in representative genera of living primates. ... The BRM index for each is given in parenthesis". This wording suggests to the reader that the basic rectangles and the indices quoted with them are "representative" of the various genera which he illustrates. But on the next page he states that what he lists in Fig. $1 B$ as "Homo sapiens, negro (116)" is not representative but is "the extreme case".

Similarly, when his Fig. $1 \mathrm{~A}$, which he entitles "Homo sapiens, white (77)" is compared with the information given elsewhere in his letter, the index of 77 which he quotes as being that of what he calls "Homo sapiens, white" is in the first place based only on what he describes as "Twelve American white mandibles" and, moreover, that these twelve yielded an average index of 86.7. The example which he illustrates with an index of 77 in Fig. $1 A$ is therefore also not representative.

At this point it is perhaps pertinent to ask what Kinzey means by "Homo sapiens, white" and "Homo sapiens, negro". Is he seriously suggesting that he believes that either the white skinned or the dark skinned populations of the United States, or of the world, are so homogeneous as to be capable of being considered valid anthropological entities?

Kinzey goes on to say that the indices which he has worked out confirm my statement that the shape of the mandibular rectangle "in living man differs clearly from that of living pongids"; but he then proceeds to adduce a great deal of special pleading in an attempt to demonstrate that this is not, in his personal view, true of the fossil representatives of the two families. In his Fig. 2, for example, he shows two excessively warped and abnormal fossil hominid mandibles, those of Australopithecus robustus (No. SK 23) and of Homo sp. (No. SK 15)* which are both from the Swartkrans site in the Transvaal, and uses them as supposed evidence that some australopithecines fall "within the estimated population range for living pongids". The evidence which he derives from these two specimens is meaningless, because the bone of both specimens is known to be badly warped and this has been stated in print many times. It must also be pointed out that careful reconstructions of what these mandibles must have looked like before they were warped have been published.

Kinzey does state that he realizes that some of his measurements "may be based on warped specimens" and, moreover, his

* Telanthropus capensis has now been shown to be Homo. The specific name capensis is invalid for Homo, having been used before. measurements are chiefly based on "casts or photographs", not on the original specimens. Yet he does not hesitate to use such evidence to support his theory, without apparently checking with the institutions where the originals are kept.

Later in his letter he says: "the similarity in the BRM index of the two Rusinga mandibles in Fig. 2 supports the suggestion . . . that mandible No. 394 (of 1967, the Kenyapithecus mandible) is most similar in its overall morphology to Dryopithecus (Proconsul) africanus". He then goes on, "If Kenyapithecus africanus is linked clearly with the family Hominidae on the basis of the shape of the basic rectangle, then Proconsul africanus must be also". Just as in the case of treating Australopithecus robustus as lying within the range of the indices of the Pongidae on the basis of measurements taken from a photograph of the warped specimen (SK 23), so the statement about the supposed similarity of the mandible of Proconsul africanus (No. R 1947 375) to Kenyapithecus africanus (No. R 1967 384) is misleading.

Le Gros Clark and $\mathrm{I}^{2}$ made it clear that in the case of this particular Proconsul africanus specimen (No. R 1947 375), the enamel of most of the crowns of the teeth was badly damaged and broken away, the incisors and canines were all broken off and the anterior region of the alveolar margin was damaged. Unfortunately, Kinzey does not state the BRM index which he obtained by measuring our photograph of this specimen, but in his Fig. 2 he positions it at a point which gives it an approximate index of 122 . This places it, he says, "almost within the estimated population range of American negro". Actually, when I re-examined this Proconsul specimen, it became clear that there is at least $1.5 \mathrm{~mm}$ of enamel missing at the back of the third molars, and approximately $1 \mathrm{~mm}$ missing at the front of the alveolar margin. Estimated as accurately as possible from the original, the length of the basic rectangle of this specimen is $51 \mathrm{~mm}$ and the width $39 \mathrm{~mm}$ which yields a BRM index of 130.9 compared with Kinzey's index of 122 based on his measurements of the photograph. This places this Proconisul specimen well within his extended pongid range and very much further away from the position of Kenyapithecus africanus, which lies within the range of Homo sapiens, as shown by Kinzey's Fig. 2.

I assume that Kinzey accepts the theory of evolution and believes therefore that the further back the families Hominidae and Pongidae are traced, the more likely they are to be morphologically similar, whereas their present-day representatives are likely to have become more and more divergent as each specialized away from the common stock. It is therefore to be expected, as is the case, that the pongid Proconsul africanus and the hominid Kenyapithecus africanus, both from Lower Miocene deposits of Rusinga Island, would be morphologically rather more similar to each other than present-day man is to living great apes.

I never attempted to use the single factor of the shape of the basic mandibular rectangle of Kenyapithecus africanus when I decided to include it, taxonomically, within the Hominidae. I only used the evidence from the mandibular rectangle as one of a large number of different characteristics to be seen in the specimens, every one of which pointed in the same definite direction.

I suggest that when Kinzey's statements are adjusted in relation to the basic facts which I have outlined, his evidence supports rather than disproves my view that Kenyapithecus africanus is a primitive member of the family Hominidae.

\section{S. B. LeakeY}

Centre for Prehistory and Palaeontology, PO Box 30239,

Nairobi

Received January 5, 1971.

${ }^{1}$ Kinzey, W. G., Nature, 228, 289 (1970).

2 Le Gros Clark, W. E., and Leakey, L. S. B., Fossil Mammals of Africa, No. 1 (British Museum (Natural History), London, 1951). 